\title{
THE STUDY OF ELECTROCARDIOGRAPHIC AND ECHOCARDIOGRAPHIC CHANGES IN COPD
}

\author{
Talari Swathi', Dasari Nishanth Vudela², Deepika Kucherlapati³, B. Goutam ${ }^{4}$ \\ ${ }_{1}^{1}$ Senior Resident, Department of Pulmonary Medicine, Gandhi Medical College, Hyderabad. \\ ${ }^{2}$ Senior Resident, Department of Pulmonary Medicine, Government General Chest Hospital, Hyderabad. \\ 3 Senior Resident, Department of Pulmonary Medicine, Sunshine Hospital, Hyderabad. \\ ${ }_{4}^{4}$ Senior Resident, Department of Pulmonary Medicine, Holistic Hospital, Hyderabad.
}

\section{BACKGROUND}

ABSTRACT

Chronic Obstructive Airways Disease or Chronic Obstructive Pulmonary Disease is acknowledged by the WHO as the fourth commonest cause of death worldwide.

The aim of the study is to analyse various cardiovascular manifestations of "COPD" with the help of Electrocardiography and Echocardiography.

\section{MATERIALS AND METHODS}

This is a prospective observational study. Patients admitted in Department of Pulmonary Medicine, MediCiti Institute of Medical Sciences, Ghanpur with symptoms suggestive of airway obstruction of more than 2 years duration and in whom clinical diagnosis of COPD is made. They were subjected to investigations. Patients with $\mathrm{FEV}_{1} / \mathrm{FVC} \leq 0.7$ and $\mathrm{FEV}_{1}<80 \%$ of the predicted, which does not change significantly $(<200 \mathrm{~mL})$ after bronchodilator therapy with $0.3 \mathrm{mg}$ of salbutamol nebulisation were included. The included patients would undergo Electrocardiography and Echocardiography for analysis.

\section{RESULTS}

Total number of patients assessed (n): 50. Mean age of the patients in this study was 50.7. The common ECG changes seen in the present study were- Right axis deviation (28\%), Incomplete RBBB (12\%) and P Pulmonale (34\%). The Echocardiography assessment showed that $44 \%$ of patients had evidence of elevated pulmonary artery pressure, 4 patients had right atrial dilatation, and 1 patient had pericardial effusion.

\section{CONCLUSION}

Electrocardiography has high sensitivity in detecting pulmonary hypertension in chronic obstructive pulmonary disease patients as evidenced by P Pulmonale, right axis deviation, right ventricular hypertrophy. Majority of the patients with electrocardiographic evidence of pulmonary hypertension also had Echocardiographic evidence of elevated pulmonary artery pressure.

\section{KEYWORDS}

Electrocardiography, Echocardiography, COPD, Chronic Obstructive Airways Disease.

HOW TO CITE THIS ARTICLE: Swathi T, Vundela DN, Kucherlapati D, et al. The study of electrocardiographic and echocardiographic changes in COPD. J. Evolution Med. Dent. Sci. 2018;7(02):135-141, DOI: 10.14260/jemds/2018/30

\section{BACKGROUND}

Chronic Obstructive Airways Disease or Chronic Obstructive Pulmonary Disease is acknowledged by the WHO as the fourth commonest cause of death worldwide. It is projected to be the third most common cause of death and fifth most common cause of chronic disability by the year 2020. Earlier in the $20^{\text {th }}$ century TB was the major pulmonary disease in developing countries. Its place has been taken by two diseases in the latter half of $20^{\text {th }}$ century namely chronic obstructive pulmonary disease and Carcinoma of lung. Cigarette smoking is said to have been playing a major role in the aetiology of Chronic Obstructive Pulmonary Disease. Knowing the ill effects of smoking many governments including Indian Government have banned smoking in public places.

'Financial or Other Competing Interest': None.

Submission 28-11-2017, Peer Review 23-12-2017,

Acceptance 29-12-2017, Published 08-01-2018.

Corresponding Author:

Dr. Dasari Nishanth Vundela,

\#8-2-693/2/26 and 27,

Mithilanagar Colony, Road No. 12, Banjara Hills,

Hyderabad-500034, Telangana.

E-mail:d.nishanth.v@gmail.com

DOI: $10.14260 /$ jemds $/ 2018 / 30$
This may in future lead to reduction in number of smokers and its ill effects thus reducing the incidence of COAD in due course. Chronic Obstructive Airways Disease is known to cause airflow limitations, impaired gas exchange and increased pulmonary artery pressure. According to literature, prevalence of pulmonary hypertension in chronic obstructive airways disease is $18 \% .^{1}$ Elevated pulmonary artery pressure is a predictor of mortality in chronic obstructive airways disease. "Weitzenblum" and coworkers ${ }^{2}$ showed a 72\% 4-year survival in patients with normal pulmonary artery pressure compared with $49 \%$ survival in patients with an elevated pulmonary artery pressure in Chronic Obstructive Airways Disease.

Both electrocardiography and echocardiography are very useful in the detection of elevated pulmonary artery pressure. Here an attempt has been made to correlate clinical features, pulmonary function tests, electrocardiography and echocardiography in case of Chronic Obstructive Airways Disease patients.

\section{MATERIALS AND METHODS}

This present study entitled "The Study of Electrocardiographic and Echocardiographic changes in COPD" was undertaken at MediCiti Institute of Medical Sciences, Ghanpur. It is an Institution-based, prospective, 
observational study at Department of Pulmonary Medicine for a period of 2 years from January 2015 to July 2016. The study group consists of 50 patients presenting to OPD/IP for pulmonary services. All subjects were interviewed and complete history and examination was done according to a predesigned proforma. Informed consent was acquired from patients for participation in this study. Spirometry, Electrocardiography, Echocardiography, Chest X-ray PA view, haemogram and other routine investigations were performed.

\section{Inclusion Criteria}

Patients were admitted with symptoms suggestive of airway obstruction of more than 2 years duration and in whom clinical diagnosis of COPD is made. They are subjected to investigations. The patients in whom $\mathrm{FEV}_{1} / \mathrm{FVC} \leq 0.7$ and $\mathrm{FEV}_{1}<80 \%$ of the predicted, which does not change significantly $(<200 \mathrm{~mL})$ after bronchodilator therapy with 0.3 $\mathrm{mg}$ of salbutamol nebulisation are included.

\section{Exclusion Criteria}

Patients with Bronchial asthma, Tuberculosis, Clinically symptomatic patients of Ischaemic Heart Disease, Rheumatic Heart Disease, Systemic hypertension.

\section{Data Collection}

Patients attending the outpatient clinic and who were admitted in "MediCiti Institute of Medical Sciences," Ghanpur with complaints of persistent cough with expectoration for 3 months in two consecutive years or who have cough, breathlessness with clinical or x-ray evidence of hyperinflation were selected for the study. They were subjected to investigations. Patients with $\mathrm{FEV}_{1} / \mathrm{FVC} \leq 0.7$ and $\mathrm{FEV}_{1}<80 \%$ of the predicted, which does not change significantly $(<200 \mathrm{~mL})$ after bronchodilator therapy with 0.3 mg of salbutamol nebulisation were included and assessed for ECG and ECHO changes.

\section{Statistical Analysis}

Continuous and categorical data was interpreted by means of Pearson's Chi Square Test.

\section{RESULTS}

The present study entitled "The Study of Electrocardiographic and Echocardiographic Changes in Chronic Obstructive Airways disease" was conducted in Department of Pulmonary Medicine at MediCiti Institute of Medical Sciences, Ghanpur with total number of patients studied (n): 50.

\section{Anthropometric Data Age Distribution}

In the present study, the mean age of study population is 50.7 years, ranging from 50 to 61 years. Total number of cases (n): 50. $60 \%$ were of Age less than 50 years (n: 30), 32\% between Age $51-60$ years (n: 16), 8\% were of more than 60 years (n: $4)$.

\section{Sex Distribution}

In our study, $98 \%$ of the cases were male (n: 49 ) and $2 \%$ were female (n: 1$)$.
Chronic obstructive pulmonary disease is most prevalent in males.

\section{Occupation Details}

Chronic obstructive pulmonary disease is most prevalent in manual labourers $68 \%$ (n: 34 ), followed by office staff $20 \%$ (n: 10), Shop owners $8 \%$ (n: 4\%) and Homemakers 2\% (n: 1).

\section{Socioeconomic Status}

Nearly 3/4th of chronic obstructive pulmonary disease patients are from lower socioeconomic group 72\% (n: 36) and rest were from middle class $28 \%$ (n: 14$)$.

\section{Smoking Pattern}

$72 \%$ of chronic obstructive pulmonary disease patients are smokers, $83 \%$ of smokers (30 persons) still continue to smoke.

\section{Smoking Intensity}

$64 \%$ of smokers smoke $<10$ cigarettes per day. $19 \%$ of smokers smoke more than 20 cigarettes per day.

\section{Age at which Smoking was started}

Most of the patients started smoking at a younger age that is before 20 years of age.

\section{Air Pollution}

$82 \%$ (41 persons) of chronic obstructive pulmonary patients give a history of living in damp housing as well as exposure to passive smoking. One person was working in a cement factory.

\section{Analysis of Aetiological Factors}

$62 \%$ of patients gave history of exposure to both smoking and air pollution. $6 \%$ of patients gave history of no exposure to risk factors.

\begin{tabular}{|c|c|c|}
\hline X-ray Chest Findings & No. of Cases & Percentage \\
\hline Emphysematous & 22 & 44 \\
\hline Changes & 34 & 68 \\
\hline Increased Pulmonary & & 12 \\
\hline Vascular markings & 6 & 6 \\
\hline Pulmonary Artery & 3 & \\
\hline Dilatation & & \\
\hline Cardiomegaly & Table 1. Chest X-ray Findings \\
\hline \multicolumn{2}{|c|}{}
\end{tabular}

\section{Pulse 0ximetry}

$84 \%$ of patients showed no evidence of hypoxaemia. $16 \%$ of patients had evidence of hypoxaemia on pulse oximetry.

\begin{tabular}{|c|c|c|}
\hline FEV1/FVC & No. of Cases & Percentage \\
\hline $70-61$ & 31 & 62 \\
\hline $60-51$ & 12 & 24 \\
\hline$<50$ & 7 & 14 \\
\hline \multicolumn{2}{|c|}{ Table 2. Interpretation of Pulmonary Function Test } \\
\hline
\end{tabular}




\begin{tabular}{|c|c|c|c|c|}
\hline & N & Mean & $\begin{array}{c}\text { Std. } \\
\text { Deviation }\end{array}$ & $\begin{array}{c}\text { Std. } \\
\text { Error }\end{array}$ \\
\cline { 3 - 5 } & & & Mean \\
\hline PFT FEVI & 50 & 1.2040 & 0.17723 & 0.02506 \\
\hline PFT FVC & 50 & 2.0280 & 0.16418 & 0.02322 \\
\hline FEV1/FVC & 50 & 59.0400 & 5.17829 & 0.73232 \\
\hline \multicolumn{5}{|c|}{ Table 3. One-Sample Statistics } \\
\hline
\end{tabular}

\begin{tabular}{|c|c|c|}
\hline ECG Findings & No. of Cases & \% \\
\hline P pulmonale & 17 & 34 \\
\hline QRS Right Axis Deviation & 14 & 28 \\
\hline Right Bundle Branch Block & 6 & 12 \\
\hline R/s > 1 in V1 & 4 & 8 \\
\hline r/s <1 in V6 & 3 & 6 \\
\hline Poor Progression of R & 5 & 10 \\
\hline Wave in Right Precordial Leads & & \\
\hline $\begin{array}{c}\downarrow \text { T Wave Amplitude in Right } \\
\text { Precordial Leads }\end{array}$ & 2 & 4 \\
\hline \multicolumn{2}{|c|}{ Table 4. Interpretation of ECG } \\
\hline
\end{tabular}

\begin{tabular}{|c|c|c|}
\hline $\begin{array}{c}\text { ECG evidence of Pulmonary } \\
\text { Hypertension }\end{array}$ & No. of Cases & $\%$ \\
\hline Present & 23 & 46 \\
\hline Absent & 27 & 54 \\
\hline Table 5. ECG with Evidence of Pulmonary Hypertension \\
\hline
\end{tabular}

\begin{tabular}{|c|c|c|}
\hline $\begin{array}{c}\text { ECHO evidence of Pulmonary } \\
\text { Hypertension }\end{array}$ & $\begin{array}{c}\text { No. of } \\
\text { Cases }\end{array}$ & Percentage \\
\hline Present & 22 & 44 \\
\hline Absent & 28 & 56 \\
\hline Table 6. Echo Evidence of Pulmonary Hypertension \\
\hline
\end{tabular}

\begin{tabular}{|c|c|c|}
\hline Echo Findings & No. of Cases & Percentage \\
\hline Elevated PAP & 22 & 44 \\
\hline Tricuspid Regurgitation & 6 & 12 \\
\hline Right Atrial Dilatation & 4 & 8 \\
\hline Pericardial Effusion & 1 & 2 \\
\hline \multicolumn{2}{|c|}{ Table 7. Echo Findings in PHT } \\
\hline
\end{tabular}

\begin{tabular}{|c|c|c|}
\hline Pulmonary Hypertension & No. of Cases & Percentage \\
\hline Severe (>55 mmHg) & 1 & 2 \\
\hline Moderate (41-55 mmHg) & 7 & 14 \\
\hline Mild (25-40 mmHg) & 14 & 28 \\
\hline \multicolumn{2}{|c|}{ Table 8. Severity of Pulmonary Hypertension } \\
\hline
\end{tabular}

\begin{tabular}{|c|c|c|c|}
\hline Age Group & No Echo E/O PHT & Echo E/O PHT & Total \\
\hline <50 Years & 19 & 11 & 30 \\
\hline 50 -60 Years & 6 & 10 & 16 \\
\hline$>60$ Years & 3 & 1 & 4 \\
\hline Total & $\mathbf{2 8}$ & $\mathbf{2 2}$ & $\mathbf{5 0}$ \\
\hline Table 9. Age Group with Echo Evidence Pulmonary \\
Hypertension \\
\hline
\end{tabular}

$\mathrm{P}=0.177$ Not significant

\begin{tabular}{|c|c|c|c|}
\hline \multirow{2}{*}{ Smoking } & \multicolumn{2}{|c|}{ ECHO evidence of PHT } & Total \\
\cline { 2 - 4 } & Absent & Present & \\
\hline Absent & 13 & 1 & 14 \\
\hline Present & 15 & 21 & 36 \\
\hline Total & 28 & 22 & 50 \\
\hline \multicolumn{3}{|c|}{ Table 10. Correlation of Smoking with } \\
Echo Evidence of PHT \\
\hline
\end{tabular}

$\mathrm{P}=0.001$ significant.

\begin{tabular}{|c|c|c|c|}
\hline Air Pollution & \multicolumn{2}{|c|}{ Echo Evidence of PHT } & Total \\
\hline & Absent & Present & \\
\hline Absent & 4 & 4 & 8 \\
\hline Present & 24 & 18 & 42 \\
\hline Total & $\mathbf{2 8}$ & $\mathbf{2 2}$ & $\mathbf{5 0}$ \\
\hline \multicolumn{3}{|c|}{ Table 11. Correlation of Air Pollution with } \\
Echo Evidence of PHT \\
\hline
\end{tabular}

$P=0.709$ Not significant.

\begin{tabular}{|c|c|c|c|}
\hline Smoking & \multicolumn{2}{|c|}{$\begin{array}{c}\text { Echo Evidence of } \\
\text { PHT }\end{array}$} & Total \\
\hline Intensity (Cigarettes/Day) & Absent & Present & \\
\hline No smoking & 13 & 1 & 14 \\
\hline$<5$ & 7 & 6 & 13 \\
\hline $6-10$ & 6 & 4 & 10 \\
\hline $11-20$ & 2 & 4 & 6 \\
\hline$>20$ & 0 & 7 & 7 \\
\hline Total & $\mathbf{2 8}$ & $\mathbf{2 2}$ & $\mathbf{5 0}$ \\
\hline Table 12. Correlation of Smoking Intensity with Echo \\
Evidence of PHT \\
\hline
\end{tabular}

$\mathrm{P}=0.001$ significant.

\begin{tabular}{|c|c|c|c|}
\hline \multirow[t]{2}{*}{ ECG Evidence of PHT } & \multicolumn{2}{|c|}{ Echo Evidence of PHT } & \multirow[t]{2}{*}{ Total } \\
\hline & Present & Absent & \\
\hline Present & 18 & 5 & 23 \\
\hline Absent & 4 & 23 & 27 \\
\hline Total & 22 & 28 & 50 \\
\hline Table 13. Correlation & $\begin{array}{c}\text { CG Evide } \\
\text { PHT }\end{array}$ & $\pi$ & \\
\hline
\end{tabular}

$\mathrm{P}=$ Not significant

Pulmonary artery catheterisation is the gold standard for measurement of pulmonary artery pressure. If we take Doppler echocardiogram measurement of pulmonary arterial pressure as the standard procedure, sensitivity and specificity of ECG evidence of pulmonary hypertension can be measured by Wilson score.

\begin{tabular}{|c|c|c|}
\hline Parameters & Estimates & $\begin{array}{c}\text { Lower - upper } \\
95 \% \text { CI's }\end{array}$ \\
\hline Sensitivity & $81.82 \%$ & $\begin{array}{l}(61.48,92.69) \\
\text { Wilson Score }\end{array}$ \\
\hline Specificity & $82.14 \%$ & $\begin{array}{c}(64.41,92.12) \\
\text { Wilson Score }\end{array}$ \\
\hline Positive Predictive Value & $78.26 \%$ & $\begin{array}{l}(58.1,90.34) \\
\text { Wilson Score }\end{array}$ \\
\hline Negative Predictive Value & $85.19 \%$ & $\begin{array}{c}(67.52,94.08) \\
\text { Wilson Score }\end{array}$ \\
\hline Diagnostic Accuracy & $82 \%$ & $\begin{array}{l}(69.2,90.23) \\
\text { Wilson Score }\end{array}$ \\
\hline $\begin{array}{l}\text { Likelihood Ratio of } \\
\text { Positive Test }\end{array}$ & 4.589 & 3.022-6.947 \\
\hline $\begin{array}{l}\text { Likelihood Ratio of } \\
\text { Negative Test }\end{array}$ & 0.2213 & $0.1331-0.3681$ \\
\hline Diagnostic odds & 20.7 & $4.844-88.45$ \\
\hline \multicolumn{3}{|c|}{ Table 14. Screening Test Evaluation } \\
\hline
\end{tabular}

Electrocardiography has high sensitivity and specificity in the detection of pulmonary hypertension. 


\section{DISCUSSION}

Chronic Obstructive Pulmonary Disease (COPD) is a major cause of chronic morbidity and mortality, being $4^{\text {th }}$ leading cause of death worldwide and further increase in its prevalence and mortality can be expected in coming years. This disease process is manifested by progressive airflow limitation, hyperinflation and air trapping, hypoxaemia, hypercapnia, and elevations in pulmonary vascular pressure. Clinically, individuals with COPD develop breathlessness, cough, sputum production and disease exacerbations that impair quality of life. Factors that portend a poor prognosis include severity of airflow limitation, ventilator capacity, hypercapnia, and pulmonary hypertension. ${ }^{3}$ Cardiovascular manifestations are most important among them. Pulmonary arterial hypertension (PAH) and chronic cor pulmonale are major cardiovascular complications. Right ventricular dysfunction is common in patients with COPD particularly in those with low oxygen tension. It can further reduce exercise tolerance, increase dyspnoea and decrease in functional status. Patients with COPD also carry increased risk of mortality due to cardiac arrhythmias, ischaemic heart disease, myocardial infarction, and congestive heart failure. Pulmonary hypertension in COPD is placed in group 3 of the 2003 WHO classification of PAH, i.e., PAH associated with disorders of the respiratory system and/or hypoxaemia. PAH associated with lung diseases defined as resting mean PAP (mPAP) greater than $20 \mathrm{mmHg}$, which is different from the definition of primary pulmonary hypertension (mPAP $>25$ mmHg). ${ }^{4}$ In India, COPD is the second most common lung disorder after pulmonary TB. ${ }^{5}$ Pulmonary arterial hypertension develops late in the course of COPD with the development of hypoxaemia $\left(\mathrm{PaO}_{2}<8 \mathrm{KPa}, 60 \mathrm{mmHg}\right)$ and usually hypercapnia. It is the major cardiovascular complication of COPD and is associated with the development of Right ventricular hypertrophy (cor pulmonale) ${ }^{6}$ and with poor prognosis. ECG criteria for detecting right ventricular hypertrophy have a reasonably high specificity, but have a relatively low sensitivity. ${ }^{7}$ Detectable tricuspid regurgitation by Echo Doppler is probably the best technique to measure pulmonary artery pressure non-invasively. ${ }^{6}$

\section{ECG Changes}

The common ECG changes seen in the present study wereRight axis deviation (28\%), Incomplete RBBB (12\%) and P Pulmonale (34\%). Similar observations were made in study by Niranjan Mambally Rachaiah et al. ${ }^{8}$ In their study, incidence of RAD was $42 \%$, RBBB was seen in $4 \%$ patients and P Pulmonale seen in $42 \%$ patients.

\begin{tabular}{|c|c|c|}
\hline ECG Changes & $\begin{array}{c}\text { Niranjan Mambally } \\
\text { Rachaiah et al }^{8}\end{array}$ & $\begin{array}{c}\text { Present } \\
\text { Study }\end{array}$ \\
\hline RAD & $42 \%$ & $28 \%$ \\
\hline Incomplete RBBB & $4 \%$ & $12 \%$ \\
\hline P Pulmonale & $42 \%$ & $34 \%$ \\
\hline \multicolumn{2}{|c|}{ Table 15. ECG Changes } \\
\hline
\end{tabular}

In our study, chronic obstructive pulmonary disease is present almost exclusively in males. This is due to increased prevalence of smoking in males. According to literature, after standardisation for smoking males are at high risk than females. ${ }^{9}$ In the present study, males accounted for $98 \%$ of the study population. $2 \%$ were female.

\begin{tabular}{|c|c|c|}
\hline Study & $\begin{array}{c}\text { Percentage of } \\
\text { Male Patients }\end{array}$ & $\begin{array}{c}\text { Percentage of } \\
\text { Female Patients }\end{array}$ \\
\hline RL Agarwal et al ${ }^{10}$ & 66.7 & 70 \\
\hline Lazovic B et al ${ }^{11}$ & 70 & 30 \\
\hline Present study & 98 & 2 \\
\hline \multicolumn{2}{|c|}{ Table 16. Sex Distribution } \\
\hline
\end{tabular}

Most of the chronic obstructive pulmonary disease patients start smoking at a younger age (in teenage). Normally lung growth is maximal by the late teenage years, and lung function is relatively constant until the late $20 \mathrm{~s}$.

\section{Mean Age Distribution}

In the present study, mean age of distribution of COPD is 50 years. The mean age in RL Agarwal et al ${ }^{10}$ study was 37.8 .

\begin{tabular}{|c|c|}
\hline Study & Mean age (yrs.) \\
\hline RL Agarwal et al $^{10}$ & 37.8 \\
\hline Present Study & 50 \\
\hline \multicolumn{2}{|c|}{ Table 17 } \\
\hline
\end{tabular}

Smoking teenagers do not achieve the peak value of their non-smoking contemporaries and begin to lose lung function as soon as growth ceases. ECG and Echo evidence of pulmonary hypertension is more common in smokers who smoke more than 20 cigarettes per day than those who smoke less or those who do not smoke. The role of smoking in the pathogenesis of chronic obstructive pulmonary disease received considerable attention in the 1960s. By the late 1970s, it was clear that the earliest lesions demonstrable in smokers affected the small airways- i.e., small bronchi and bronchioles. ${ }^{12,13}$ The harmful effects of smoking can be manifested primarily by catarrh as well as by limitation of flow of these two types, the catarrhal is more common; it occurs in about $80 \%$ of smokers. Also, the volume of sputum production is not directly related to limitation of airflow. ${ }^{14,15}$ In some persons, the predominant effect of smoking may be hypertrophy of mucous glands and hypersecretion; in others, it may damage small airways, destroy alveolar walls, and modify elastic recoil of the lungs.

In a 40 -year followup of British physicians, the annual mortality per 100,000 from chronic obstructive pulmonary disease was 10 for those who never smoked and 225 for those who smoked more than 25 cigarettes daily; rates were intermediate for former smokers and those who smoked fewer than 25 cigarettes per day. ${ }^{16}$ Many people with a significant number of pack-years still have a normal or near normal FEV1 while some people have reduced FEV1 with relatively modest smoking history. Whether low tar cigarette brands produce less severe chronic obstructive pulmonary disease (analogous to bronchogenic carcinoma) is unclear. Smokers are not a reliable source of information about their own smoke inhalation, and there is no simple means of quantifying smoking patterns to determine the connection between patterns of smoke inhalation and development of chronic obstructive pulmonary disease. It's not possible to predict which $15 \%$ of smokers go on to develop chronic obstructive pulmonary disease. Chronic obstructive pulmonary disease is more common in manual workers of which most of them have been exposed to smoking since teen years. The high prevalence of smoking among workers has been a major confounding factor. $72 \%$ of chronic obstructive 
pulmonary disease patients are from lower socioeconomic status. These may be related to the possible low birth weight (Barker hypothesis), childhood malnutrition or damp housing facilities. In our studies, $16 \%$ of patients have pulse oximetry evidence of hypoxaemia. According to American Thoracic Society they are candidates for long term home oxygen. In our studies $46 \%$ of patients have ECG evidence of right ventricular strain. $34 \%$ of persons have ECG evidence of $p$ Pulmonale. According to ATS, they are candidates for long term home Oxygen at a higher $\mathrm{SaO}_{2}$ level.

\section{P Pulmonale}

In the present study, peaked P-wave i.e. amplitude more than $2.5 \mathrm{~mm}$, was recorded in $34 \%$ of the patients, whereas it was seen in $35.7 \%$ of the cases with COPD in the Study by RL Agarwal et al.10

In Spodicks ${ }^{17}$ series, $13.9 \%$ of COPD patients had P-wave equal or greater than $2.5 \mathrm{~mm}$. Scott et al ${ }^{18}$ recorded same incidence of $32.7 \%$ in their studies.

\begin{tabular}{|c|c|}
\hline Study & Percentage of p Pulmonale \\
\hline RL Agarwal et al ${ }^{10}$ & $35.7 \%$ \\
\hline Spodicks ${ }^{17}$ series & $13.9 \%$ \\
\hline Scott et al 18 & $32.7 \%$ \\
\hline Lazović $\mathrm{B}$, et al11 & $14.54 \%$ \\
\hline Present study & $34 \%$ \\
\hline
\end{tabular}

\section{ECG Evidence of Pulmonary Hypertension in COPD Patients}

According to literature, many patients have ECG changes suggestive of RV strain but didn't manifest RV strain by Echocardiography.

Fishman-standard criteria for right ventricular hypertrophy in ECGs were absent in $2 / 3^{\text {rd }}$ of chronic obstructive pulmonary disease patients who had right ventricular hypertrophy on post-mortem examination. ${ }^{19}$

ECG of prognostic importance in severe chronic obstructive pulmonary disease has been outlined by KokJensaw. In a study of 288 patients, survival was very poor in individuals with a QRS axis of +90 degrees to +180 degrees and amplitude of $\mathrm{p}$ wave in lead II of $2 \mathrm{~mm}$ or more. Only $37 \% \& 47 \%$ respectively of patients with these changes were alive after 4 years.

In V.K. Singh and S.K. Jain study 20 of 130 patients of chronic obstructive pulmonary disease, effect of airflow obstruction on ECG findings such as p>2.5 mm, QRS axis equal or more than +90 degrees, $\mathrm{R}$ wave in V6 less than or equal to $5 \mathrm{~mm}, \mathrm{R} / \mathrm{S}$ ratio in $\mathrm{V} 5, \mathrm{~V} 6$ equal to or less than 1 shows a negative correlation with FEV1/FVC ratio. Other features like $\mathrm{T}$ wave amplitude, negative "p" wave in avL, $\mathrm{S}$ wave more than $5 \mathrm{~mm}$ in depth in V5, V6 and SI, SII, SIII patterns were observed less frequently and correlate weakly with severity of disease.

In a study involving 50 plantation workers attending General Hospital, Tata Tea Ltd, Munnar, Kerala, good correlation between severity of COPD and number of abnormal ECG manifestations was present. ${ }^{21}$

In a case control study involving 50 cases \& 50 controls, age and sex matched ECG features of RAD and RV strain, and Echo features of right chambers and pulmonary artery enlargements were compared. According to the study, subclinical cor pulmonale and severity of right-sided haemodynamic disturbances can be measured accurately. ${ }^{22}$

In a study involving 25 COPD patients of R G Kar Medical College, Calcutta, ECG and Echo findings were compared. ECG evidence of RVH i.e. P pulmonale, right axis deviation, RBBB, clockwise rotation was present in $50 \%$ of patients. Echo evidence of right ventricular hypertrophy and elevated pulmonary artery pressure were found in $85 \%$ of cases. ${ }^{23}$

The study was conducted by Putnik M, Povazan D, VindisJesic $\mathrm{M}$ et $\mathrm{al}^{24}$ aiming at evaluating the possibilities of electrocardiography and echocardiography in establishing the diagnosis of chronic pulmonary heart disease. Sixty patients with a chronic obstructive pulmonary disease (COPD) and clinical symptoms of cardiac decompensation (CPHD) were observed. The examined patients ranged from 26 to 74 years of age, the mean age being 59.25 years. The diagnosis of CPHD was established by electrocardiography in 43 patients $(78.18 \%)$ while in 57 patients $(95 \%)$ it was done by ultrasound cardiography. Morphologic changes of the right ventricle (RV) were quantified, i.e. the diagnosis of chronic pulmonary heart disease was confirmed by echocardiography parameters such as right ventricle free wall thickness, end diastolic right ventricle dimension and tricuspid regurgitation. The information on the right ventricle function was provided by the values of echocardiography parameters, right ventricle ejection fraction--RVEF and right ventricle systolic pressure-RVSP. Monitoring of these values after therapy, gave a good insight into the therapy effects. Echocardiography has been concluded to be of better sensitivity than ECG in diagnosing CPHD and both methods, non-invasive and easily applicable, have an important role in examining cardiac changes in patients with COPD.

A study was conducted by Prakash R.25 about "Echocardiographic diagnosis of right ventricular hypertrophy: correlation with ECG and necropsy findings in 248 patients." Measurements of right ventricular wall thickness (RVWT) by echocardiography and at necropsy correlated well $(\mathrm{r}=0.83)$ in 36 patients. Echocardiography had a sensitivity of $93 \%$ and a specificity of $95 \%$ in diagnosing right ventricular hypertrophy (RVH) at necropsy; electrocardiography (ECG) had a sensitivity of $31 \%$ and a specificity of $85 \%$ in diagnosing RVH. An additional 212 patients were studied by echocardiography and ECG. Based on echocardiographic criteria of RVH (RVWT Greater Than or Equal to $5 \mathrm{~mm}$ ), 134 of 212 patients had RVH, and 78 were without RVH; the ECG had a sensitivity of $27 \%$ and a specificity of $88 \%$ for diagnosing RVH when correlated with the echocardiographic criteria. Diagnosis of RVH was difficult by ECG in 73 patients due to conduction defects or old myocardial infarction; the RVWT measurements were useful in evaluating RVH in these patients.

In our study, $44 \%$ of patients have Echo evidence of elevated pulmonary artery pressure. 4 patients had right atrial dilatation. 1 patient had pericardial effusion. Both right atrial enlargement and pericardial effusion show poor prognosis.

In the study by NK Gupta et al, ${ }^{26}$ Cor Pulmonale was seen in $17.5 \%$ patients. Study done in 1958 by Himelmann et $\mathrm{al}^{27}$ showed incidence of Cor Pulmonale as $75 \%$. Hence incidence of cor Pulmonale in COPD is variable. 


\begin{tabular}{|c|c|}
\hline Study & Cor pulmonale \% \\
\hline NK Gupta et al 26 & $17.5 \%$ \\
\hline Himelmann et al27 & $75 \%$ \\
\hline Present study & $44 \%$ \\
\hline \multicolumn{2}{|c|}{ Table 19. Echo Evidence of Cor pulmonale } \\
\hline
\end{tabular}

\section{CONCLUSION}

1. Chronic obstructive pulmonary disease is more common in males.

2. Smoking is the principle cause of chronic obstructive pulmonary disease.

3. Severity of Chronic obstructive pulmonary disease is directly proportional to intensity of smoking.

4. Severity of Chronic obstructive pulmonary disease is associated with starting smoking at a younger age (in teenage).

5. Most patients are from low socioeconomic status.

6. Electrocardiography has high sensitivity in detecting pulmonary hypertension in chronic obstructive pulmonary disease patients as evidenced by $\mathrm{P}$ pulmonale, right axis deviation, right ventricular hypertrophy. Majority of the patients with electrocardiographic evidence of pulmonary hypertension also had Echocardiographic evidence of elevated pulmonary artery pressure. So both Electrocardiography and Echocardiography are very useful in the assessment of severity of chronic obstructive pulmonary disease.

\section{REFERENCES}

[1] Arcasoy SM, Christie JD, Ferrari VA, et al. Echocardiographic assessment of pulmonary hypertension in patients with advanced lung disease. Am J Respircrit Care Med 2003;167(5):735-40.

[2] Weitzenblum E, Hirth C, Ducolone A, et al. prognostic value of pulmonary artery pressure in COPD. Thorax 1981;36(10):752-8.

[3] Elwing J, Panos RJ. Pulmonary hypertension associated with COPD. Int $\mathrm{J}$ Chron Obstruct Pulmon Dis 2008;3(1):55-70.

[4] Shujaat A, Minkin R, Eden E. Pulmonary hypertension and chronic cor pulmonale in COPD. Int J Chron Obstruct Pulmon Dis 2007;2(3):273-82.

[5] Sharma SK. Chronic obstructive pulmonary disease. In: Munjal Y, Sharma SK. eds. API Text book of medicine. $9^{\text {th }}$ edn. New Delhi, India: Jaypee Brothers Medical Publishers (P) Ltd., 2012:1711-18.

[6] Macnee W. Chronic bronchitis and emphysema. In: Seaton A, Seaton D, Leitch G. eds. Crofton \& Douglas's respiratory diseases. $5^{\text {th }}$ edn. Blackwell Science Ltd., 2000:625-704.

[7] Oswald-Mammasser M, Oswald T, Nyankiye E, et al. Non-invasive diagnosis of pulmonary hypertension in COPD comparison of ECG radiological measurements, echocardiography and myocardial scintigraphy. Eur J Respire Dis 1987;71:419-29.

[8] Rachaiah NM, Rachaiah JM, Krishnaswamy RB. A correlative study of spirometric parameters and ECG changes in patients with chronic obstructive pulmonary disease. Int $\mathrm{J}$ Biol Med Res 2012;3(1):1322-6.
[9] Pride NB, Burrows B. Development of impaired lung function: natural history and risk factors. Chapter 4 . In: Calvereley P, Pride NB. eds. Chronic obstructive pulmonary disease. London: Chapman and Hall 1995:69-91.

[10] Agarwal RL, Kumar D, Gurpreet, et al. Diagnostic values of electrocardiogram in chronic obstructive pulmonary disease (COPD). Lung India 2008;25(2):7881.

[11] Lazović B, Svenda MZ, Mazić S, et al. Analysis of electrocardiogram in chronic obstructive pulmonary disease patients. Med Pregl 2013;66(3-4):126-9.

[12] Hogg JC. Bronchiolitis in asthma and chronic obstructive pulmonary disease. Clinical Chest Med 1993;14(4):733-40.

[13] Hogg JC, Macklem PT, Thurlbeck WM. Site and nature of airway obstruction in COLD. New Engl J Med 1968;278(25):1355-60.

[14] Fletcher C, Peto R. The natural history of chronic airflow obstruction. Br Med J 1977;1(6077):1645-8.

[15] Hale KA, Ewing SL, Gosnell BA, et al. Lung disease in long-term cigarette smokers with and without chronic air-flow obstruction. Am Rev Respir Dis 1984;130(5):716-21.

[16] Doll R, Peto R, Wheatley K, et al. Mortality in relation to smoking: 40 years' observations on male British doctors. Br Med J 1994;309(6959):901-11.

[17] Spodick DH, Hauger-Kelvene JH, Tyler JM, et al. The electrocardiogram in pulmonary emphysema. Relationship of characteristic electrocardiographic findings to severity of disease as measured by degree of airway obstruction. Am Rev Resp Dis 1963;88(1):14-19.

[18] Scott RC, Kaplan S, Fowler NO, et al. The electrocardiographic pattern of right ventricular hypertrophy in chronic cor pulmonale. Circulation 1955;11(6):927-36.

[19] Fishman AP. Hypoxia on the pulmonary circulation. How and where it acts. Circ Res 1976;38(4):221-31.

[20] Singh VK, Jain SK. Effects of airflow limitations on ECG in chronic obstructive airways disease. Indian J Chest Diseases Alied Sci 1989;31(1):1-8.

[21] Vijayakumar S, Kutty AK, Prabhu G, et al. Electrocardiographic profile in chronic obstructive pulmonary disease. Prof. Vishwanathan poster session. Apicon 2002.

[22] Mistry PJ, Bhattacharya AK, Pathak KJ. Echocardiography in chronic obstructive pulmonary diseases. Prof. Vishwanathan M. poster session. Apicon 2002.

[23] Dhar MC, Chaudhari S, Halder U, et al. Electrocardiographic changes in chronic cor pulmonale with chronic obstructive pulmonary disease. Prof. Vishwanathan poster session. Apicon 2002.

[24] Putnik M, Povazan D, Vindisjesic M. Electrocardiography and echocardiography in the diagnosis of chronic cor pulmonale (Article in Serbo Croatian (Roman) Med Pregl 1998;51(11):528-31. 
[25] Prakash R. Echocardiographic diagnosis of right ventricular hypertrophy: correlation with ECG and necropsy findings in 248 patients. Cathet Cardiovasc Diagn 1981;7(2):179-84.

[26] Gupta NK, Agarwal RK, Srivastav AB, et al. Echocardiographic evaluation of heart in chronic obstructive pulmonary disease patient and its correlation with severity of disease. Lung India 2011;28(2):105-9.
[27] Himelmann RB, Struve SN, Brown JK, et al. Improved recognition of cor pulmonale in patients with severe chronic obstructive pulmonary disease. Am J Med 1988;84(5):891-8. 